\title{
El Inca Garcilaso, la lengua materna y la legitimación de la historia ${ }^{1}$
}

\author{
José Luis Rivarola \\ Università di Padova
}

En memoria de

Alberto Escobar

A mediados del siglo XVI la aventura americana de España entraba en una etapa de relativa estabilidad. En efecto, el segundo de los virreinatos creados por la Corona para administrar las posesiones ultramarinas y para encauzar la acción descubridora v colonizadora aún inconclusa, a saber, el virreinato de Nueva Castilla o del Perú, iniciaba su consolidamiento institucional, apenas acabadas las feroces guerras civiles que habían ensangrentado el territorio en la década del 40.

Coincidentemente, transcurrido ya más de medio siglo de novedad americana, la información sobre la realidad del Nuevo Continente y sobre los sucesos ocurridos en ể, thanşmitida hasta entonces a través de cartas y relaciones sobre todo de participantes y testigos, comienza a ser materia de una historiografía de propósitos más ambiciosos, en cuyo ejercicio coincidían los historiadores ocasionales y los 'profesionales', tanto si tenían experiencia directa de América cuanto si, no teniéndola, se basaban en testimonios de informantes y en consulta libresca o documental.

Un caso de estos últimos es el de Francisco López de Gómara, quien, sin haber estado nunca en América, escribió una Historia general de las

1 El presente texto se leyó como ponencia plenaria en el congreso "Valladolid: corte y cultura", realizado en Valladolid en noviembre de 1996. 
Indias en dos extensas partes, una dedicada a todo el continente -con un tercio referido al Perú- y otra específicamente a la conquista de México. La Historia de Gómara tuvo un éxito notable apenas aparecida: luego de la primera edición zaragozana de 1552 hubo seis más en los dos años siguientes, fuera de varias versiones al italiano y al francés publicadas a partir de 1556 y de 1559 , respectivamente. Es un éxito fácil de explicar: la obra de Gómara es un compendio excelente en cuanto a la riqueza del contenido y al estilo de la prosa. Después de su lectura, no puede uno sino sumarse al juicio del ilustre historiador peruano Raúl Porras Barrenechea, quien ha dicho de ella: "es un oasis de amenidad, de concisión y clásica elegancia de la frase, en medio del fárrago de otros cronistas. Tuvo el don de la síntesis, supo narrar con agilidad y brevedad largas y cansadas jornadas y trazar en rasgos rápidos, sugestivos e irónicos, el retrato de sus personajes en frases que tienen siempre un relieve de proverbio o de medalla" ${ }^{2}$. Por cierto que nada de esto implica que sus informaciones fuesen siempre válidas o fidedignas, ni que deba compartirse el sesgo de sus enfoques o la rotundidad de algunos de sus juicios. Pero luego volveré sobre esto, a propósito del tema central de la presente exposición. Permítaseme agregar antes algunos datos sobre Gómara, pues lo requiere su función introductoria en el desarrollo de dicho tema.

La biografía de Gómara no se conoce de modo seguro y al pormenor, pero tampoco carecemos de algunos datos ${ }^{3}$. Nacido en Soria en 1511, se había formado, a lo que parece, en Alcalá de Henares, donde se ordenó sacerdote y profesó quizá la enseñanza de Retóriça. Su obra historiográfica lo revela poseedor de una buena cultura hưmanistica, que hábia reforzado durante una estancia en Italia ${ }^{3 b i s}$. A su retorno a España entra al servicio de Hernán Cortés, quien había vuelto de México en 1540 y se había establecido en Valladolid.

2 Los cronistas del Perú (1528-1560), Lima (Banco de Crédito) 1986, p. 191.

3 Cf. E. de Vedia, "Noticia de la vida y escritos de Francisco López de Gómara", en Historiadores primitivos de Indias, Madrid, B.A.E., 22, 1852-53, pp. XIII-XV; F. López de Gómara, Annals of the Emperor Carlos V, ed. por Bigelow Merriman, London 1912; H.R. Wagner, Francisco López de Gómara, Berkeley, 1924. Vid. también el prólogo y la cronología a cargo de Jorge Gurría Lacroix en la edición de F. López de Gómara, Historia general de las Indias y Vida de Hernán Cortés, Caracas (Biblioteca Ayacucho 64), 1979.

3bis Véase ahora L. Bénat-Tachot, "La Historia General de las Yndias de Francisco López de Gómara: Ydentificación de las fuentes y elaboración textual", en I. Arellano y J.A. Rodríguez Garrido (eds.), Edición y anotación de textos coloniales hispanoamericano, YberoamericanaVervuert, Madrid 1999, pp. 75-95. 
El cargo de capellán de la casa y familia del entonces ya Marqués del Valle no estuvo reñido con la afición historiográfica del clérigo soriano, quien durante este primer período vallisoletano preparó su Chronica de los muy nombrados Omich y Haradin Barbarrojas (conocida como Crónica de los Barbarrojas) y su Historia general de las Indias (llamada también en la segunda edición Hispania Victrix). Luego de dos años en Castilleja de la Cuesta acompañando a Cortés hasta la muerte de éste en 1547, Gómara vuelve a Valladolid al servicio del hijo del conquistador y escribe en esta ciudad sus Anales del emperador Carlos V. En Valladolid permanece hasta su muerte, ocurrida probablemente en $1564^{4}$.

Aquí nos interesa, naturalmente, la obra que ha cimentado la fama americanista de Gómara. En lo que respecta a las fuentes de la Historia general, se han podido identificar algunas de las de carácter libresco, aunque quedan vacíos por llenar al respecto. Pero no cabe duda de que gran parte del conocimiento histórico elaborado por Gómara en su obra proviene de relaciones orales que obtuvo en el entorno indiano de la casa de Cortés, de seguro mayoritariamente mexicano. Para la segunda parte de su obra, es decir, para la Conquista de México Gómara pudo servirse, pues, de numerosos testigos, entre ellos, por cierto, del propio Cortés, que lo orientaron hacia una versión lisonjera, cuya excesiva personalizaciơn en Cortés mismo llevó, como se sabe, a Bernal Díaz a escribir su Verdadera Historia. Pero también tuvo Gómara informantes con experiencia directa en otros ámbitos ultramarinos. Es claro que sobre el Perú pudo valerse dé alguien que conocía la minucia sobre hechos y personajes, y que se la fransmitió guntor con" sus valoraciones, con sus filias y con sus fobias. Tratándose en gran parte de historia reciente, de la que numerosos protagonistas, así como amigos o parientes de ellos, vivían aún, es fácil entender las susceptibilidades que podían tocarse. En uno de los capítulos sobre las guerras civiles del Perú, por ejemplo, Gómara cuenta que estando por ser ajusticiado el maestre de campo de Gonzalo Pizarro, Francisco de Carbajal -famoso personaje que siglos más tarde fue inmortalizado literariamente por Ricardo Palma en sus Tradiciones peruanas- y habiendo ido a visitarlo el capitán Diego Centeno, figura importante del campo realista vencedor, aquél manifestó conocerlo porque nunca lo había visto sino de

4 Otras obras de Gómara son: Historia de las guerras navales desde el año que nació el Emperador don Carlos nuestro señor hasta el que murió (ms.) y Inquiridion de cosas notables sucedidas por mar y por tierra en tiempo de nuestro Emperador don Carlos nuestro señor (ms.). 
espaldas, aludiendo así a la presunta cobardía de Centeno. Nada más elocuente que la siguiente anécdota narrada por el Inca Garcilaso para ilustrar algunas de las reacciones que podían suscitar versiones como la señalada. Estas son las palabras de Garcilaso:

Es assí que un soldado de los más principales y famosos del Perú, que vino a España poco después que salió la historia de Gómara, topándose con él en Valladolid, entre otras palabras que hablaron sobre el caso le dixo que por qué avía escrito y hecho imprimir una mentira tan manifiesta, no aviendo pasado tal. Con éstas le dixo otras palabras que no se zufre ponerlas aquí, a las quales respondió Gómara que no era suya la culpa, sino de los que davan las relaciones nacidas de sus passiones. El soldado le dixo que para esso era la discreción del historiador, para no tomar relación de los tales, ni escrivir mucho sin mirar mucho, para no disfamar con sus escritos a los que merecen toda honra y loor. Con esto se apartó Gómara muy confuso y pesante de aver escrito lo que levantaron a Carvajal en dezir que no conocía a Diego Centenos.

Ya se ve cómo en ese Vallađolid en el que había muerto el gran Almirante, en el que había estado preso Hernando Pizarro, hermano del Marqués Gobernador del Perú, en el que había pasado-sus últimos años Cortés, resonaba la polémica sobre las cosas de América. de Letras

Pero tan elocuentes como esta della anécdota son las reacciones que se pueden recoger de las abundantes anotaciones manuscritas a un ejemplar de la Historia general de las Indias que hoy conserva la Biblioteca Nacional del

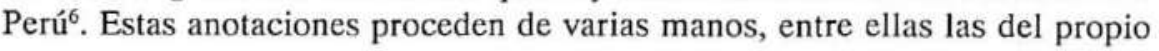

5 Cito por la primera edición de la Historia general del Perú, Córdoba, Viuda de Andrés Barrera, 1617, Libro V, cap. XL (mantengo la grafia original, pero resuelvo abreviaturas sin indicarlo cada vez y uniformo $u$ consonántica como v. Además agrego acentos y puntúo con criterio moderno.

6 Se trata de un ejemplar de la edición impresa en Zaragoza en 1554, del cual hay reproducción facsimilar (I.ima, Comisión del Quinto Centenario del Descubrimiento de América-Encuentro de dos mundos, 1993), si bien no fiable en lo que respecta a las anotaciones manuscritas, que han sido objeto de retoques deformantes. El ejemplar en cuestión fue dado a conocer por Raúl Porras Barrenechea en "Una joya bibliográfica peruana", publicado originariamente en El Comercio de Lima en 1948 y luego reeditado varias veces, la última en el libro citado en la nota 2, pp. 753-767. Porras Barrenechea inició el estudio de estas 
Inca Garcilaso. Si algunas son simples marcas de reparo en la lectura o tienen un carácter resumidor, otras rectifican y condenan al autor en tono fuertemente polémico. Así, por ejemplo, un anotador, que no es el Inca, al iniciarse en la obra de Gómara la parte sobre el descubrimiento y la conquista del Perú, lanza el siguiente anatema, que revela la lectura anterior de todo lo siguiente:

grande agravio se le haze a tierra y rey y a sus descubridores y conquistadores en le creer a esta historia

anatema que continúa, luego de una parte de difícil lectura, con una suerte de contraposición entre armas y letras, que apunta a desacreditar al escritor. En efecto, nuestro anotador anónimo encomia a

los que supieron realizar(?) hazañas más que relatarlas?.

En otro lugar, el anotador recusa la veracidad de los informantes de Gómara y los considera dignos de la hoguera, a la par del libro:

Escrive por relaciones, dize mill diparates, porque los que se las davan, por hazerse muy pláticos con él, davan de dezirle quanto se les venía a la boca y asi escrivió mentiras en perjuizio de cavalleros y personas muy principales, que merecía que quemaran el libro y a quien hizola relacióncå de Letras

Las observaciones "Jeqe Inca tienen un tono mas"moderado que las del anotador anterior, si bien en algunas ocasiones tampoco Garcilaso puede evitar el dar rienda suelta a la indignación que le produce una frase de

anotaciones, sobre las cuales puede verse ahora también J.L.R., "El taller del Inca Garcilaso. Sobre las anotaciones manuscritas en la Historia General de las Indias de F. López de Gómara y su importancia en la composición de los Comentarios Reales", Revista de Filología Española LXXV, 1995, pp. 56-84.

7 Se trata de la anotación en el margen derecho del folio XLIX r., que está muy deteriorada y se lee con mucha dificultad. En las citas omito los signos de la reconstrucción, que pueden verse en el trabajo citado en la nota anterior.

8 Lo citado es la parte final de una larga anotación rectificatoria, que no parece del Inca, a lo que dice Gómara en los folios LXXXVII v. y LXXXVIII r. (he mantenido la ortografia del ms., aunque regularizando la $u$ consonántica como $v$, poniendo acentos, separando palabras y puntuando según criterios modernos; lo mismo vale para las citas anteriores y las siguientes. 
Gómara. Así, debajo de aquella en la que Gómara dice que los indios "viven como sodomitas, hablan como moros y parecen judíos" escribe:

Pues ni son judíos ni moros sino gentiles, mal que os pese a vos y a quien os dio la relación ${ }^{9}$

La segunda parte de esta anotación, más emotiva que propiamente rectificatoria, está tachada, quizá por el mismo Garcilaso, arrepentido del exabrupto. En efecto, el temperamento mesurado del Inca se revela en la mayoría de sus notas, que no por eso son menos tajantes y cuestionadoras.

$\mathrm{Y}$ en este punto podemos volver nuestra mirada a los Comentarios reales. Bien se sabe que esta obra nació de una intención rectificatoria respecto de la historiografía anterior, como se ve ya desde el Proemio, donde el Inca señala que su propósito, respecto de los historiadores españoles, es "servirles de comento y glosa y de intérprete en muchos vocablos indios, que, como estranjeros en aquella lengua, interpretaron fuera de la propriedad della"10. Como se ve por esta declaración de principio, el conocimiento de la lengua indígena ocupa un lugar prioritario en el diseño historiográfico del Inca, pues sólo ese conocimiento permite interpretar adecuadamente determinados fenomenos históricos y culturales. A esta comprobación parece haber llegado Garcilaso justamente a través de la lectura de Gómara. Varias de sus anotaciones inciden en los errores del cléfigosoriano y en los malentendidos lingüísticos. Veamos un ejemplo. Cuando Gómara en el f. Lly se refiere a un episodio ocurrido a la llegada de los espanoles a Tumbes, apunta que tres de ellos caen en manos de los indios, quienes los entregan a sus sacerdotes para que

los sacrificassen a cierto ídolo del sol llamado Guaca, llorando, y no por compassión, sino por costumbre que tienen de llorar delante la Guaca, y aun Guaca es lloro y guay voz de recién nacidos" ${ }^{11}$

La anotación de Garcilaso es breve y contundente:

9 Folio LVII v.

10 Cito por la ed. de C. Pacheco Vélez, Lima (Banco de Crédito del Perú) 1985, p. 4 (cit. Comentarios).

1 Folio Ll v. Cito por la edición de Zaragoza, 1554, objeto de las anotaciones que comento. 
No sabe lo que se dize en la exposición del vocablo. Confunde dos vocablos de distintas significaciones, como se declarará en nuestra Historia del Perú.

El propósito de diferir la rectificación hasta lo que después serían los Comentarios reales no se concreta, pues folios después, cuando Gómara insiste en decir "Entran en los templos llorando y guayando, que guaca eso quiere dezir ${ }^{12}$, Garcilaso no se contiene, subraya la frase subordinada y anota largamente la ligereza lingüística de Gómara. Veamos:

...escrive cossas muy agenas de la significación del vocablo que expone y por tanto muy lejos de la verdad, como es en la significación de estos nombres guacha o guaca, para lo cual es de saber que, aunque las letras parecen uno mismo difieren en la pronunciación y por ella en la significación: que el un nombre que significa 'ídolo' se pronuncia la postrera sílaba hiriendo con la lengua en el paladar, que, pues que no tenemos letras en la lengua española con que hazer las tales pronunciaciones, me pareció compararlas a las que hazen la urraca y el cuervo en sus graznidos: que la urraca pronuncia afuera en el paladar y el cuervo dentro en las fauces, pues pronunciando como la urraca significa ídolo y pronunciando como el cuervo significa Horar ${ }^{13}$.

Esta larga explicacion paso, con algunas modificaciones -por ejemplo, se suprimió la comparación ornifológeca pafa diferenciciar un sonido velar y otro postvelar- a los Comentarios, justamente al libro II, donde el Inca discurre sobre la religión incaica. Lo mismo acaece con varias otras anotaciones al texto de Gómara, que fueron sin duda el germen de la escritura más elaborada de los Comentarios.

En esta obra, como he adelantado, la competencia lingüística del historiógrafo es la clave hermenéutica fundamental para la reconstrucción legítima de la historia y de la cultura precolombina. Ahora bien, el Inca no sólo la emplea en tanto tal, sino que hace de ella una materia constante de

12 Fofio LV v.

13 Cito a partir de mi propia reconstrucción (cf. el trabajo anteriormente citado), pero modernizando en el sentido ya señalado. 
reflexión justificadora. Ya al comienzo mismo de la obra aparecen unas Advertencias de carácter lingüístico, las cuales, por lo demás, constituyen un esbozo de fonética contrastiva español-lengua general del Perú, como entonces se decía a lo que hoy conocemos como quechua. Pero, en verdad, a lo largo de todo el texto se reclama la atención del lector sobre el tema de la lengua materna del autor.

Veamos el asunto más de cerca, a fin de que podamos desentrañar algunas de las estrategias discursivas y retóricas del Inca en sus Comentarios. La noción de lengua materna y su expresión a través de este sintagma surgieron en la alta Edad Media, probablemente cuando se reconoció que el antiguo sermo patrius, es decir, el latín, se había separado en dos distintas variedades, una ya relativamente artificial aprendida en la escuela, y otra que se adquiría naturalmente y que fue asociada a la madre y a la casa. Esta lengua natural o materna fue, además, vinculada a la lactancia, por un camino metafórico que parte del Nuevo Testamento ${ }^{14}$. Pero es sobre todo en los siglos XVI y XVII que la lengua materna, aludida generalmente a través del tópico de la lengua "mamada en la leche", es objeto de fervorosos elogios y de defensas por parte de numerosísimos ingenios de la época, dentro de los cuales podemos mencionar a Juan de Valdés, a Fray Luis de León, a Cervantes... El Inca Garcilaso, pues, se inscribe en un contexto ilustre, si bien el elogio mismo cede paso en él a la consideración de que la lengua materna da legitimidad a su propia versión de la historia. Y̧aśś Garcilaso contrapone la lengua indígena, que considera materna, al español, al que califica de "ajeno", con un adjetivo que en las apologías quinientistas de la lengua vulgar se aplicaba al latín.

Pero el español para el Inca, en verdad, no era "ajeno". Lo que se sabe de su infancia y juventud ${ }^{16}$ hace pensar más bien en que tanto la lengua

14 Para un tratamiento amplio de este asunto y la evaluación de la bibliografia al respecto puede verse J.L.R., "La lingua materna 'mamada en la leche'. Origine, interpretazione e funzione di un topos nell'Inca Garcilaso", Cultura neolatina LVII, 1997, pp. 325-344. En el presente artículo se traducen y resumen los aspectos esenciales que contiene el que se acaba de citar.

15. Cf.: "Esta larga relación del origen de sus Reyes me dio aquel Inca, tío de mi madre, a quien yo se la pedi, la cual yo he procurado traduzir fielmente de mi lengua materna, que es la del Inca, en la ajena, que es la castellana..." (Comentarios, Libro I, cap. XXVII, p. 32).

16 Cf. al respecto A. Miró Quesada, El Inca Garcilaso, Lima (Universidad Católica del Perú) 1994. 
indígena como la española fueron adquiridas en la primerísima infancia, y que luego esta última fue ejercitada en la etapa escolar, junto con la latina. Quizá haya sido esta circunstancia la que colaboró a este juicio de "alienación" respecto del castellano, visto restrospectivamente -en términos de Juan de Valdés- como "pegadizo" y "aprendido por libros", mientras que el quechua, por no haber sido materia de estudio en esa etapa de formación, quedaba aureolado de espontaneidad, de naturalidad y de intimidad. Por lo demás, el español se convirtió prontamente en la primera lengua de nuestro personaje, ya no en sentido cronológico relativo al momento estricto de la adquisición, sino en el sentido de la lengua de la cual se valdría toda su vida de modo prioritario y probablemente casi exclusivo a partir del viaje a España. Parece, pues, que Garcilaso no tenía demasiadas razones objetivas para contraponer de modo tan marcado la lengua indígena a la española, ya que ambas le eran naturales y nativas. Pero a su propósito convenía, por cierto, subrayar, respecto de lengua materna, la acepción "lengua de la madre" como opuesta a "lengua del padre", como le convenía insistir asimismo en el tópico ya referido de la lactancia, pues el uso de una fórmula de amplia vigencia en la cultura renacentista permitía cimentar la confiabilidad, cuando no la inapelabilidad, de la opinión propia y, en general, Ta validez de todo el discurso historiográfico, el cual aparece fundado en una competencia lingüística presentada como la única con carácter de primaria y originaria. Esta competencia permite la adecuada interpretación de la cultura de que ella forma parte, pues da un acceso privilegiado a las fuentes de la tradición oral, transmitida al historiador por sus parientes indígenas o como dice él reiterando el tópico, "mamada en la leche"14. Noobstante, de este modor se desbalanceaba. respecto de la lengua y, cuando menos, en el nivel de la declaración explicita, ese equilibrio bicultural que el Inca en varios otros momentos pone de relieve como realizado en su persona. En todo caso, el hecho de que la superioridad historiográfica de nuestro autor deriva también de su competencia paralelamente nativa en la otra lengua quedaba sólo implicado como premisa no

17 "...por lo cual se me permitirá dezir lo que conviniere para la mejor noticia que se pueda dar de los principios, medios y fines de aquella monarquía, que yo protesto dezir llanamente la relación que mamé en la leche..." (Comentarios, Libro I, cap. XIX, p. 35); “... de manera que no dezimos cosas nuevas, sino que, como indio natural de aquella tierra, ampliamos y estendemos con la propria relación la que los historiadores españoles, como estranjeros, acortaron, por no saber la propiedad de la lengua ni haver mamado en la leche aquestas fábulas y verdades como yo las mamé..." (Comentarios, Libro II cap. X, p. 64); "Yo escrivo, como otras vezes he dicho, lo que mamé en la leche y vi y oí a mis mayores" (Comentarios, Libro III, cap. XXI p. 128). 
explícita, aunque no por eso menos determinante. Cabe señalar aquí que, a fin de cuentas, la condición de posesor parejamente hábil de las dos lenguas en contacto y en conflicto fue una de las razones decisivas de la fama y de la vigencia historiográfica del Inca -que pasan por la excelencia literaria de su prosa española-, frente a algunos otros cronistas indios o mestizos que no alcanzaron un bilingüismo o un biculturalismo análogo y que quedaron atrapados -aparte, por cierto, otras circunstancias- por las deficiencias y las limitaciones de su dominio del español. Pero el relegamiento, por lo menos declarativo, del castellano a ese segundo plano de lengua "ajena" le servía al Inca para tender también una especie de barrera protectora frente a eventuales críticas, es decir, tenía una finalidad similar a las reiteradas declaraciones de modestia vinculada a su condición de "indio", indio que, en verdad, propiamente no era ${ }^{18}$. Aquí y allá se trata, pues, de estrategias discursivas y retóricas que deben ser interpretadas en el contexto de las motivaciones y de los propósitos del conjunto de la construcción historiográfica.

Por otra parte, no se puede dejar de reconocer que la lengua indígena había sido una lengua iletrada -hecho que Garcilaso, hombre de cultura escrita, lamentaba amargamente ${ }^{19}$-, que expresaba a una cultura de tradición oral y que pertenecía al pueblo vencido, razones por las cuales requería un especial énfasis reivindicativo, en este caso asociado a su función como instrumento hermenéutico; la reivindicación, así, asume una dimensión distinta a la que podía tener en lel casocde das lenguas vylgares europeas que eran materia de las apologías quinientisłas, cuanto más gue en la época no faltan utilizaciones deprecatorias del tópico de la lactancia en relación con las lenguas y las culturas indígenas, en el sentido de advertirse el peligro de que los niños españoles sean contaminados espiritualmente por sus nodrizas indígenas o mestizas, y a través de esa lengua que justamente se "mama en la leche" ${ }^{20}$.

18 Trata de este asunto J.A. Rodríguez Garrido, "La identidad del enunciador en los Comentarios reales" (Revista Iberoamericana LXI, 172-173, 1995, pp. 371-383). Del análisis pormenorizado resulta que Garcilaso se presenta como indio cuando le interesa transmitir esta imagen en ciertos contextos; en otros, más bien, evita cuidadosamente esta identificación.

Cf. Comentarios, Libro VII. cap. VIII.

20 Cf. B. Lavallé, Las promesas ambiguas. Criollismo colonial en los Andes. Lima (Instituto Riva-Agüero, Universidad Católica del Perú) 1993, pp. 48-50. 
El propósito de Garcilaso de cuestionar a todos aquellos que se ocupasen de idioma o cultura indígena sin tener un conocimiento "materno" de la lengua se muestra en la anécdota que se narra en el Libro II de los Comentarios:

Veráse el descuido dellos (i.e. de los españoles) por lo que me passó con un religioso dominico que en el Perú havía sido cuatro años catredático de la lengua general de aquel Imperio, el cual, por saber que yo era natural de aquella tierra, me comunicó y yo le visité muchas vezes en san Pablo de Córdova. Acaeció que un día, hablando de aquel lenguaje y de las muchas y diferentes significaciones que unos mismos vocablos tienen, di por ejemplo este nombre Pacha, que, pronunciado llanamente, como suenan las letras españolas, quiere dezir mundo universo, y también significa el cielo y la tierra y el infierno y cualquiera suelo. Díxo entonces el fraile: "Pues también significa ropa de vestir y el axuar y muebles de casa". Yo dixe: "Es verdad, pero dígame Vuestra Paternidad ¿qué diferencia hay en la pronunciación para que signifique esso?". Díxome: "No la se". Respondíle: "Haviendo sido maestro en la lengua iñora esto? Pues sepa que para que signifique axuar o ropa de vestir han de pronunciar la primera sílaba apretando los labios y rompiéndolos con el aire de la voz, de manera que suene el romperlos". Y Yle mostré la pronunciación deste nombre y de otros viva voce, que de otra mạnera no se puede enseñar. De lo cual el catredático "y posademás Teligiosos que séplallaron a la plática se admiraron mucho ${ }^{21}$.

Ahora bien. este fragmento nos pone sobre la pista de otro problema de gran importancia en los Comentarios reales en relación con la lengua y con las concepciones lingüísticas de Garcilaso. Existe la sospecha de que el fraile aludido por el Inca en la anécdota que acabo de citar fuese nada menos que Fray Domingo de Santo Tomás, dominico autor de la primera gramática y el primer vocabulario del quechua, publicados justamente en Valladolid en 1560. Ahora, Fray Domingo, según modernos estudios sobre el tema ${ }^{22}$, no describió

21 Comentarios, Libro II, cap. V, p. 54.

22 Cf. R. Cerrón-Palomino, "El Inca Garcilaso y la lealtad idiomática", Lexis XV, 1991, pp. 133-178 y "Los fragmentos de gramática quechua del Inca Garcilaso", Lexis XVII, 1993, pp. 219-257. 
la variedad cuzqueña del quechua sino más bien otra basada en un dialecto central y que parece haber sido una especie de koiné utilizada en gran parte del imperio. Sea como fuese, en esa variedad no existía la oposición entre labiales con y sin glotalización, de modo que entre pacha "tierra", etc. y pacha "axuar", etc., había relación de homonimia. Garcilaso, pues, juzgaba desde la mira de su propia variedad lingüística, que consideraba el verdadero quechua, la lengua cortesana, con el prestigio de la capital imperial. Es probable que el detalle de la inexistencia de la oposición mencionada lo desconociera nuestro autor, así como también otros similares que se encuentran en la obra, aunque ciertamente no desconocía la existencia misma de variedades dialectales, a las cuales juzgaba con un criterio centralista y aristocrático como formas degeneradas y corruptas. Uno de los propósitos examinados en las Advertencias ya mencionadas es atajar la "corrupción" que los españoles introducen en la lengua, alterando su "propriedad" y "pureza". La ejemplificación que ocurre en la obra, sin embargo, sólo en parte puede ser retrotraída a interferencias del español; muchos casos de esta "corrupción" son, en verdad, casos de formas dialectales del mismo quechua, en parte difundidos por la koiné aludida, formas, por lo tanto, que muchos de los cronistas e historiadores españoles no hicierón sino recoger en sus obras. Pero Garcilaso no distingue, o, en todo caso, la distinción no parece interesarle. En uno de los pasajes rectificatorios, en el cual apela justamente, como se verá, al tópico de la lactancia, mete en el mismo saco a los españoles y a los hablantes "maternos" de otras variedades lingüísticas indígenas:

Esto puse áqur fi.e. lacexplicación correctả del nombre Viracocha) para los curiosos que holgaran de ver la interpretación de este nombre tan común, y cuánto se engañan en declarar el lenguaje del Perú los que no lo mamaron en la leche de la misma ciudad del Cozco, aunque sean indios, porque los no naturales della también son estranjeros y bárbaros en la lengua, como los castellanos ${ }^{23}$.

Lo que campea aquí es un conjunto de ideales renacentistas respecto de las formas superiores de lengua, en cuya determinación confluyen los criterios regionales (aquí la lengua del Cuzco) y sociales (aquí lengua cortesana), y que deben estar caracterizadas por su estabilidad normativa y por la perfección de su cultivo. Nociones como las de "propiedad" y "pureza" sirven a la caracterización de este ideal. Recuérdese cómo Juan de Valdés, castellano de 
Toledo, intenta desacreditar la autoridad de Nebrija aludiendo a su condición de andaluz y por la razón de que en Andalucía, según él, la lengua "no sta muy pura"24. La corrupción" de la lengua, es decir, su transformación y degeneración a partir de un estado de equilibrio y armonía, a causa, fundamentalmente, de factores externos (como se pensaba en Europa desde Flavio Biondo, el famoso humanista italiano del Cuatrocientos) -factores que en el pasaje de los Comentarios recién citado están representados por los españoles y por los hablantes "bárbaros" de la misma lengua indígena-, sólo puede ser contrarrestada por una conciencia alerta que no condescienda a las deformaciones y que tenga como norte "sustentar" la lengua en su pureza originaria. En esto no hay nada de particularmente original en el pensamiento del Inca, salvo en lo que significaba el referir estas ideas a un contexto tan diverso. es decir, a una lengua de tradición gráfica recentísima, que, por lo demás, no era ya sino un idioma diglósicamente inferior.

Él mismo sólo pudo contribuir a la lengua que consideraba materna a través de la descripción que de ella nos ofrece en el contexto de su obra historiográfica, descripción que no por fragmentaria es menos relevante y adecuada en la mayor parte de los casos, según ha comprobado la investigación moderna ${ }^{25}$. Al hilo de la reconstrucción histórica, a cuyo servicio puso su competencia en la lengua que era expresión de la civilización de sus parientes maternos, enunció numerosas ideas e hizo numerosas observaciones de sorprendente modernidad en varios terrenos, por ejemplo en el de las relaciones entre lengua y euttura 6 entrelengua-yentalidad, al punto de que se ha visto anticipadblene Algunas eihificiones stel Inca la concepción humboldtiana de la "forma interior del lenguaje" (innere Sprachform) ${ }^{26}$. Y aunque no se quiera llegar a tanto, hay que admitir que, de todos modos, corresponde al Inca Garcilaso un lugar en la historia de la reflexión lingüística, en particular, en los capítulos de la lingüística contrastiva y de la etnolingüística.

Paradójicamente -si aceptamos la dicotomía implícita en la utilización sui generis que hizo del concepto de lengua materna- es en la lengua "pa-

24 Diálogo de la lengua, ed. de C. Barbolani, Madrid (Cátedra) 4a. ed. 1990, p. 124.

25 Cf. los estudios ya citados de Cerrón-Palomino.

${ }^{26}$ Cf. A. Escobar, "Lenguaje e historia en los Comentarios reales", en Patio de Letras 3, Lima 1995 , pp. 1-22 (or. publicado en 1960). 
terna", lengua que él llama "ajena", pero que era, en un diferente sentido, tan materna como la otra, en la que pudo expresarse como hombre de cultura y realizar también ampliamente sus ideales estilísticos, a través de una prosa historiográfica a la que la tradición crítica ha reconocido compactamente una alta calidad literaria. Hasta qué punto el español también debía ser "sustentado en su pureza", para emplear sus palabras referidas a la lengua indígena, y no ser víctima de interferencias deformadoras (ni siquiera en salvaguarda de la "pureza" de la otra lengua), se refleja en un detalle aparentemente mínimo de las dichas Advertencias introductorias: al explicar allí cómo no existe plural en quechua aunque sí partículas que significan pluralidad, añade: "Si algún nombre indio pusiere yo en plural, será por la corrupción española o por el buen adjetivar las dicciones, que sonaría mal si escriviéssemos las dicciones indias en singular y los adjetivos o relativos castellanos en plural" 27 .

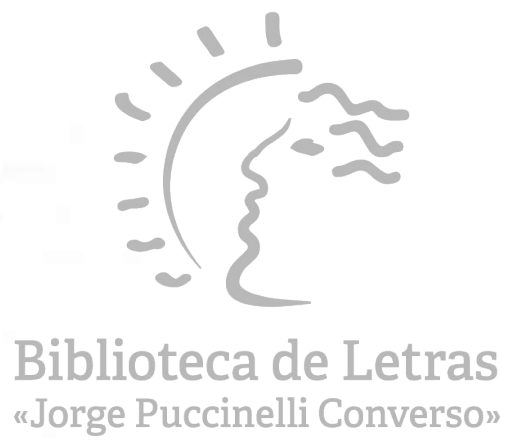

27. Comentarios, p. 6. 